\title{
Uso da Khan Academy como Avaliação Continuada em Matemática Elementar
}

\author{
Adriana V. M. de Azevedo ${ }^{1}$, Luiza L. T. de Medeiros ${ }^{1}$, Vitor H. C. Bezerra ${ }^{1}$, Antonio I. \\ S. de Oliveira ${ }^{1}$ \\ ${ }^{1}$ Instituto Metrópole Digital - Universidade Federal do Rio Grande do Norte (UFRN) \\ Av. Sen. Salgado Filho, 3000 - Lagoa Nova, CEP: 59.078-970 - Natal - RN - Brasil \\ \{adrianavmazevedo, lorenatoscanoufrn, vitorhenrique908\}@gmail.com, \\ igoroliveiradimd.ufrn.br
}

Abstract. This paper presents the experience report about the use of the Khan Academy (KA) platform to assist in the learning process of students of the Elementary Mathematics of the Bachelor in Information Technology. The methodology employed is the use of online platform activities as a continuous assessment throughout the semester using $K A^{\prime}$ 's tools and the Obama platform to recommend and collect the grades. Satisfactory results were obtained for both teachers and students, as well as more practicality and agility to apply the method and improve the approval rate.

Resumo. Este artigo apresenta o relato de experiência acerca do uso da plataforma Khan Academy (KA) com o objetivo de auxiliar no processo de aprendizagem dos alunos da disciplina Matemática Elementar do Bacharelado em Tecnologia da Informação (BTI). A metodologia empregada consiste no uso de atividades online da plataforma como uma avaliação continuada ao longo do semestre, utilizando ferramentas da própria KA e da plataforma Obama para recomendar e coletar as notas. Obtiveram-se resultados satisfatórios, tanto para o docente quanto para os alunos, como mais praticidade e agilidade para aplicar o método e uma melhoria no índice de aprovação.

\section{Introdução}

As disciplinas da área de matemática do BTI costumam apresentar taxas de reprovação elevadas. Ademais, a quantidade elevada de ingressantes anualmente no BTI fazem com que o nível de conhecimento matemático seja muito heterogêneo. Nesse contexto, a grade curricular de matemática do BTI passou por muitas modificações em seu primeiro semestre onde a principal disciplina era Matemática Elementar (ME). Porém, não só uma reformulação da grade resolveria o problema. Assim, tornam-se evidentes a necessidade de implantar metodologias auxiliares de abordagem para o conteúdo.

Foi proposto o método aplicado em turmas de cálculo relatado em Oliveira, Melo e Junior (2018) com os ajustes necessários para a realidade da disciplina. Esse método utiliza a plataforma Khan Academy (KA) como um reforço no auxílio do processo de aprendizagem dos alunos, permitindo assim uma melhor evolução na disciplina, procurando reduzir as taxas de reprovação.

Segundo Pavanelo, E.; Lima, R. (2017) no ingresso dos estudantes a universidade, verifica-se dificuldades no acompanhamento de uma disciplina ministrado com o rigor 
simbólico-formal de alto nível, que é o buscado na disciplina $\mathrm{ME}$, com vista de preparar à demanda de matemática do curso.

Com isso, no presente artigo, detalhamos como foi a utilização desse método nos alunos da disciplina ME na busca dos resultados almejados. Foi criado uma equipe para acompanhamento e desenvolvimento da disciplina no projeto de pesquisa "Uso da Khan Academy como prática auxiliar de ensino".

Por fim, este artigo está estruturado com: Introdução, onde o leitor é apresentado ao tema tratado e que o fundamentou; Metodologia, onde é descrito o método utilizado, a composição da equipe e ações no desenvolvimento do projeto; Resultados e Discussões, onde são apresentados alguns dados obtidos; Conclusões, onde é analisado o trabalho e indicado as próximas ações do grupo; e as Referências utilizadas.

\section{Metodologia}

Esta metodologia foi aplicada com os alunos da disciplina de Matemática Elementar nos dois semestres de 2018 e no primeiro semestre de 2019.

Assim como nas turmas de Cálculo I, o professor aplicou atividades online após o término de cada conteúdo (com o prazo de entrega até a próxima aula presencial de cada turma) com o intuito de potencializar o estudo continuado por parte dos alunos. Porém, desta vez, utilizou o sistema de recomendações da plataforma KA, como mostrado na Figura 1.

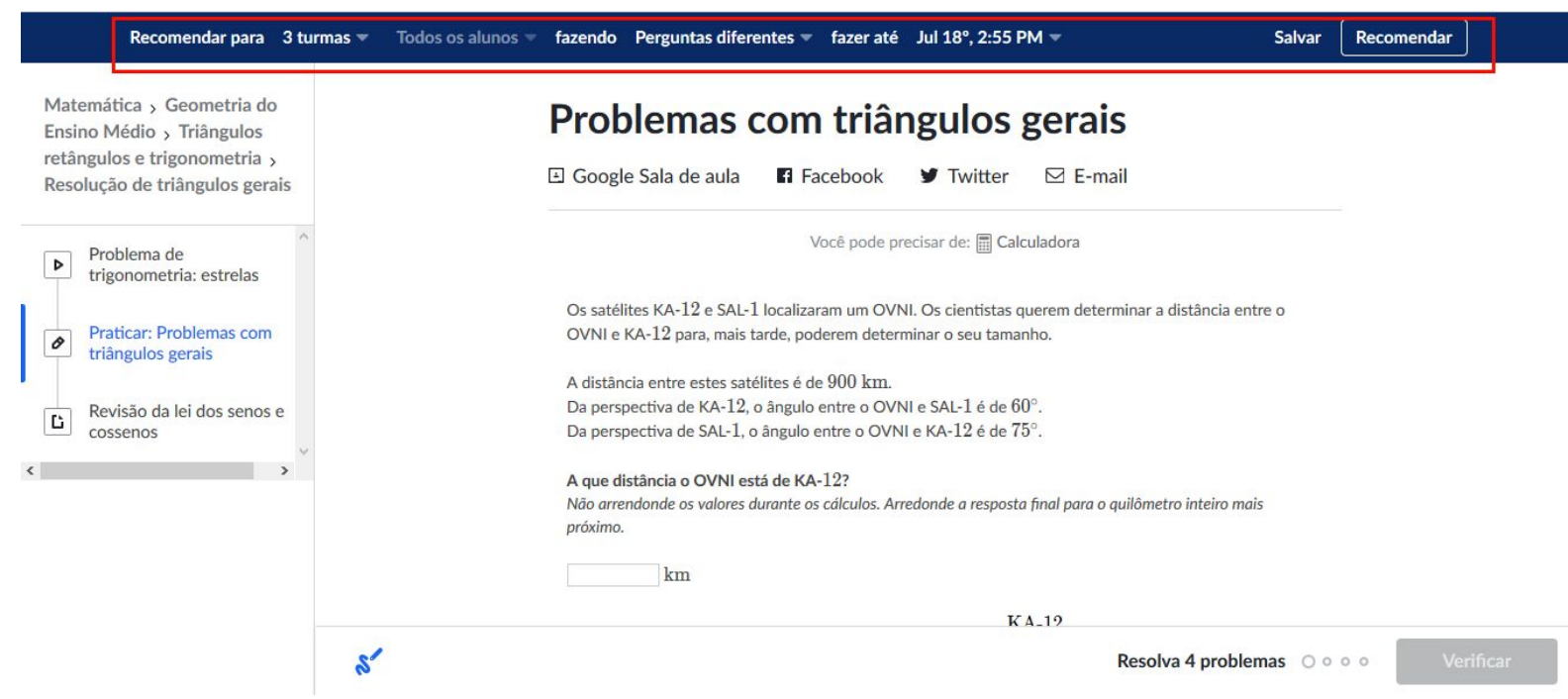

Figura 1. Página da Khan Academy com destaque para aba de recomendações

As atividades serviram como uma avaliação continuada que compôs parte da nota de cada unidade da disciplina. A média aritmética das porcentagens de desempenho nas atividades online da unidade totalizava 2,0 pontos e a avaliação escrita valia 8,0 pontos, por levar em conta todo o desenvolvimento e fundamentação das soluções dos estudantes.

De acordo com Azevedo, A.; Moraes, C. (2018) com a KA foi possível formular uma avaliação identificando as dificuldades e déficits dos alunos e também gerou um estímulo no 
progresso de rendimento escolar dos discentes, a experiência ocorreu no ensino fundamental, porém os recursos existentes na plataforma permite que os acompanhamentos sejam adequados para o ensino superior.

A plataforma educacional KA foi fundamental pois, além de disponibilizar as atividades online, dispõe de opções para que o professor acompanhe o desempenho dos seus alunos. Uma dessas opções é uma planilha de extensão Comma-Separated Values (CSV). Nela é possível identificar o exercício recomendado, a pontuação máxima dele e a pontuação do discente naquela atividade. Essas informações viabilizaram o desenvolvimento de um projeto que retira os dados fornecidos pelo arquivo gerado na plataforma KA. Uma nova planilha fornecendo somente a pontuação por aluno atendendo os critérios previamente estabelecidos pela equipe pedagógica.

Tal funcionalidade, que ainda se encontra em fase de testes, foi desenvolvida para estar integrada a uma plataforma web Objetos de Aprendizagem para Matemática (OBAMA) que, além de ser uma plataforma com referências para objetos de aprendizagem catalogados, permite a criação e compartilhamento de plano de aula [Batista et al 2017].

No desenvolvimento do projeto identificou-se uma dificuldade, que foi o cadastro de usuário na KA, tornando-se necessário a criação de um padrão de identificação. Foi solicitado aos discentes que seu nome de usuário na KA teria que ser o nome completo seguidos de underline e matrícula do mesmo na instituição.

De posse do arquivo CSV fornecido pela KA, o professor precisa apenas fazer o upload deste na plataforma Obama. Logo em seguida, ele teria a possibilidade de baixar uma nova planilha com o nome dos alunos, o desempenho destes em cada atividade online sugerida e a média desse desempenho.

\section{Resultados e Discussões}

A Tabela 1 mostra a média do desempenho na KA de 0 a 10 para os alunos aprovados e reprovados das turmas que foram alvo da metodologia no semestre 2019.1. Ao comparar o desempenho dos dois grupos, é evidente a relação entre maior desempenho na KA e aprovação dos alunos. Porém, ao analisar o desvio padrão entre os reprovados, observa-se que nem todos os alunos com alto desempenho na KA obtiveram a aprovação. Dois supostos motivos para isso é o tipo de avaliação na prova discursiva, indo de encontro às questões objetivas da KA; ou a facilidade para burlar o desempenho nas atividades da KA pois há a possibilidade de repetir quantas vezes quiser e obter a solução dos problemas. Logo, acrescentando o desvio padrão do desempenho dos aprovados, observa-se que o uso da plataforma KA como uma ferramenta de auxílio à aprendizagem nas turmas de ME é uma condição necessária para a aprovação do aluno, mas não é suficiente.

Tabela 1. Comparativo do desempenho médio na KA no semestre 2019.1

\begin{tabular}{|l|c|c|}
\hline & Aprovados & Reprovados \\
\hline Desempenho médio & 9,32 & 5,97 \\
\hline Desvio padrão & 0,94 & 2,96 \\
\hline
\end{tabular}


Por parte do docente, o uso dessa metodologia no semestre 2019.1 se mostrou mais prático e ágil pela adoção do sistema de recomendações das atividades da própria KA e da obtenção da planilha de desempenhos modificada. Nos semestres anteriores as atividades eram recomendadas através de links e a coleta do desempenho era manual, conforme Oliveira, Melo e Junior (2018).

\section{Conclusões}

Observou-se no decorrer do semestre que o método utilizado gerou um grande ganho no processo de aprendizagem da disciplina de Matemática Elementar, no qual verificou que os discentes que realizaram as atividades online apresentavam melhor desempenho qualitativo ao acompanhar as aulas, além de ter sido uma condição necessária para a aprovação.

O projeto conta também com a produção de um material textual em formato de notas de aulas, onde é trabalhado com mais afinco a parte da escrita matemática que não é comum até o ensino médio. Trabalhar os conteúdos com tal abordagem é o ponto central da disciplina e, para integralizar ao máximo a KA com esse material, um bolsista, que também foi aluno da disciplina em 2019.1, está fazendo uma análise sobre a pertinência de cada atividade da KA proposta além de pesquisar na plataforma outras atividades que seriam relevantes para ajudar o estudo dos problemas propostos nas notas de aula. A análise não é feita individualmente, ela é enriquecida por meio de depoimentos dos alunos no dia-a-dia de estudos.

O projeto ainda encontra-se em desenvolvimento, com etapas a serem alcançadas, pois além de suporte de auxílio no acompanhamento da disciplina ME, pretende-se o desenvolvimento de uma formação para professores, tanto da educação básica como superior, na utilização dos melhores recursos da plataforma da Khan Academy e suas funcionalidades, com também a ferramenta de coleta de notas desenvolvida na Obama,

Até o presente momento, os resultados obtidos estimulam muito a continuação da pesquisa.

\section{Referências}

Azevedo, A.; Moraes, C. (2018) "Khan Academy: uma ferramenta de auxílio no processo de ensino/aprendizagem da Matemática". Educação \& Linguagem. 20. 167. 10.15603/2176-1043/el.v20n1p167-182.

Batista, S. et al (2017) "OBAMA: um Repositório de Objetos de Aprendizagem para Matemática”, https://www.br-ie.org/pub/index.php/wcbie/article/view/7400, July.

Oliveira, A. I.; Melo, E. M.; Junior, J. S. (2018) "Uso da Khan Academy como Avaliação Continuada em Cálculo I", http://www.br-ie.org/pub/index.php/wie/article/view/7906, July.

Pavanelo, E.; Lima, R. (2017) "Sala de Aula Invertida: a análise de uma experiência na disciplina de Cálculo I”, In: Bolema, Rio Claro (SP), v. 31, n. 58, p. 739-759, August. 
VIII Congresso Brasileiro de Informática na Educação (CBIE 2019)

Anais do XXV Workshop de Informática na Escola (WIE 2019) 